\title{
Влияние легирования барьерных слоев на эффективность фотолюминесценции напряженных гетероструктур InGaAIAs/InGaAs/InP
}

\author{
(C) Е.С. Колодезный ${ }^{1}$, А.С. Курочкин ${ }^{1}$, С.С. Рочас ${ }^{1}$, А.В. Бабичев ${ }^{1}$, И.И. Новиков ${ }^{1}$, \\ А.Г. Гладышев ${ }^{1}$, Л.Я. Карачинский ${ }^{2}$, А.В. Савельев ${ }^{1,3}$, А.Ю. Егоров ${ }^{1}$, Д.В. Денисов ${ }^{2,4}$ \\ ${ }^{1}$ Санкт-Петербургский национальный исследовательский университет \\ информационных технологий, механики и оптики, \\ 197101 Санкт-Петербург, Россия \\ 2 ООО „Коннектор Оптикс“, \\ 194292 Санкт-Петербург, Россия \\ ${ }^{3}$ Санкт-Петербургский национальный исследовательский Академический университет \\ Российской академии наук, \\ 194021 Санкт-Петербург, Россия \\ ${ }^{4}$ Санкт-Петербургский государственный электротехнический университет „ЛЭТИ“ им. В.И. Ульянова (Ленина), \\ 197376 Санкт-Петербург, Россия \\ E-mail: anton@beam.ioffe.ru
}

(Получена 13 марта 2018 г. Принята к печати 19 марта 2018 г.)

Исследована фотолюминесценция образцов напряженных гетероструктур InGaAlAs/InGaAs/InP, выращенных методом молекулярно-пучковой эпитаксии на подложке $\operatorname{InP}(100)$, с активной областью состоящей из 9 квантовых ям $\operatorname{In}_{0.74} \mathrm{Ga}_{0.26} \mathrm{As}$ и $\delta$-легированных барьеров $\operatorname{In}_{0.53} \mathrm{Al}_{0.20} \mathrm{Ga}_{0.27} \mathrm{As}$. Исследование спектров фотолюминесценции показало, что легирование примесью $p$-типа приводит к росту эффективности фотолюминесценции при малых уровнях возбуждения по сравнению с гетероструктурой с нелегированными барьерами, а легирование барьеров до уровня $(1-2) \cdot 10^{12} \mathrm{~cm}^{-2}$ приводит к подавлению безызлучательной рекомбинации.

DOI: 10.21883/FTP.2018.09.46152.8865

\section{1. Введение}

Современное развитие физики полупроводниковых лазеров во многом связано с задачей увеличения частоты прямой токовой модуляции лазерного источника для увеличения скорости передачи информации по оптическим каналам связи [1]. Основным методом для повышения частоты в вертикально-излучающих лазерах (ВИЛ) спектрального диапазона 1300-1550 нм является увеличение дифференциального усиления активной области лазера [2] за счет повышения механического напряжения в квантовых ямах (КЯ). Однако использование данного подхода ограничено из-за невозможности создавать гетероструктуры с множественными КЯ и параметром несоответствия постоянных решетки КЯ и подложки InP более $2-2.5 \%[3,4]$. В связи с этим для дальнейшего повышения частоты необходимо комбинировать этот подход с другими, среди которых можно выделить селективное легирование активной области вблизи КЯ [5]. В данном случае подразумевается легирование тонкого слоя в матрице $\mathrm{C}$ или $\mathrm{Si}$, т. е. акцепторной и донорной примесью. Тогда изменяется зарядовое состояние КЯ, а также распределение носителей заряда между эмиттерами $p-i-n$-структуры ВИЛ и потоки электронов и дырок. Увеличение частоты релаксационных колебаний $f_{R}$, которая пропорциональна $f_{R} \propto \sqrt{\Gamma G_{\mathrm{diff}} S}$, где $\Gamma-$ темп утечки фотонов из резонатора, $S$ - число фотонов, $G_{\text {diff }}$ - дифференциальное усиление, связано со зна- чительным увеличением дифференциального усиления в легированных структурах, что приводит к росту $f_{R}$ и, потенциально, предельной частоты модуляции лазера за счет нарушения зарядовой нейтральности в КЯ при учете различной плотности распределения носителей разных знаков по энергии [6,7].

В настоящей работе мы представляем результаты исследования эффективности фотолюминесценции квантово-размерных гетероструктур спектрального диапазона 1550 нм с различным уровнем легирования углеродом (примесь $p$-типа) барьерных слоев.

\section{2. Эксперимент}

Исследуемые образцы напряженных гетероструктур InGaAlAs/InGaAs/InP были выращены методом молекулярно-пучковой эпитаксии (МПЭ) на подложке $\operatorname{InP}(100)$. Активная область гетероструктур состояла из 9 КЯ $\operatorname{In}_{0.74} \mathrm{Ga}_{0.26} \mathrm{As}$ и из широкозонных барьеров $\mathrm{In}_{0.53} \mathrm{Al}_{0.20} \mathrm{Ga}_{0.27} \mathrm{As}$, разделяющих слои КЯ. Толщина барьеров во всех гетероструктурах была одинаковая - 12 нм. Со стороны подложки и поверхности активная область ограничивалась слоями $\mathrm{In}_{0.52} \mathrm{Al}_{0.48} \mathrm{As}$. Толщина КЯ выбиралась таким образом, чтобы максимум спектра ФЛ соответствовал длине волны $1520 \pm 10$ нм, и толщина составила 2.9 нм. Были выращены образцы гетероструктур с барьерными слоями, $\delta$-легированными примесью $p$-типа (углеродом С) в 
средину барьерного слоя. Уровень легирования составил $(0.5-1.0-2.0-5.0) \cdot 10^{12} \mathrm{~cm}^{-2}$. Также была выращена контрольная гетероструктура без легирования барьеров. Спектры фотолюминесценции образцов измерялись на установке PM2000, VerteX, Nanometrics с применением InGaAs-фотодетектора.

\section{3. Результаты и обсуждение}

На рис. 1 представлены спектры фотолюминесценции (ФЛ) для трех гетероструктур с различной степенью легирования барьерных слоев, измеренные при мощности возбуждения YAG : Nd-лазера 9 MBт (длина волны генерации $532 \mathrm{нм).} \mathrm{Хорошо} \mathrm{видно,} \mathrm{что} \mathrm{пиковая} \mathrm{интенсив-}$ ность спектра ФЛ гетероструктуры со степенью легирования $2 \cdot 10^{12} \mathrm{~cm}^{-2}$ выше и его полуширина больше, чем для случая нелегированной гетероструктуры. Анализ полуширины спектра ФЛ измеренной на полувысоте спектра ФЛ (FWHM) в зависимости от уровня, возбуждения, представлен на рис. 2. Диапазон изменений полуширины спектра ФЛ составляет примерно $60-100$ мэВ и растет с повышением уровня возбуждения для нелегированной структуры, в то же время для всех легированных структур изменение очень слабое и полуширина практически не меняется с уровнем возбуждения и остается на уровне 80-86 мэВ. Причины такого поведения связаны с тем, что в легированных гетероструктурах все дырочные уровни оказываются всегда заполненными за счет поступления дырок из $\delta$-легированных слоев, и электроны, попадая в яму с определенной энергией и импульсом, всегда могут найти дырку для эффективной излучательной рекомбинации. Таким образом, рекомбинация идет через все возможные дырочные состояния вне зависимости от уровня возбуждения, что приводит к тому, что уже при минимальном уровне возбуждения полуширина спектра ФЛ близка к максимально возможному значению для основного уровня в КЯ.

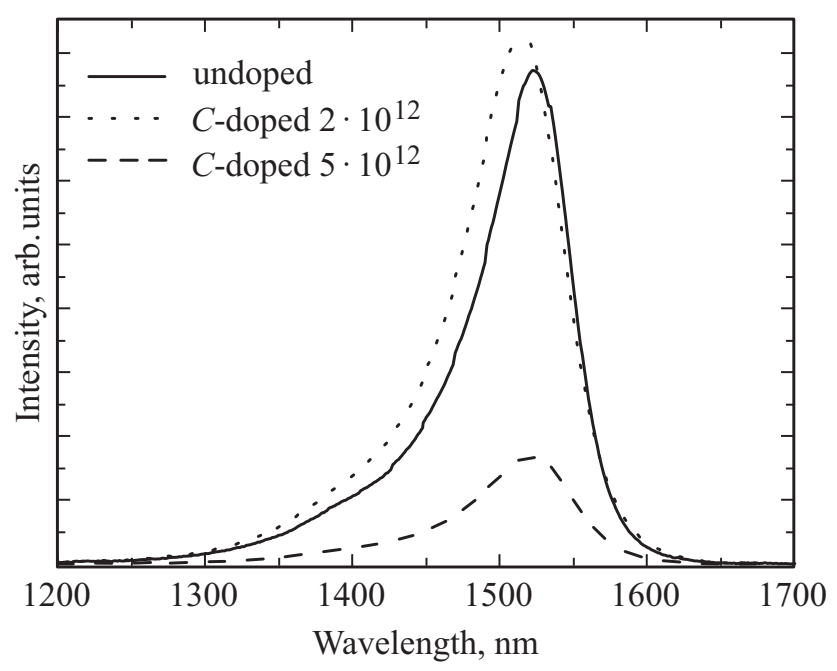

Рис. 1. Спектры фотолюминесценции гетероструктур.

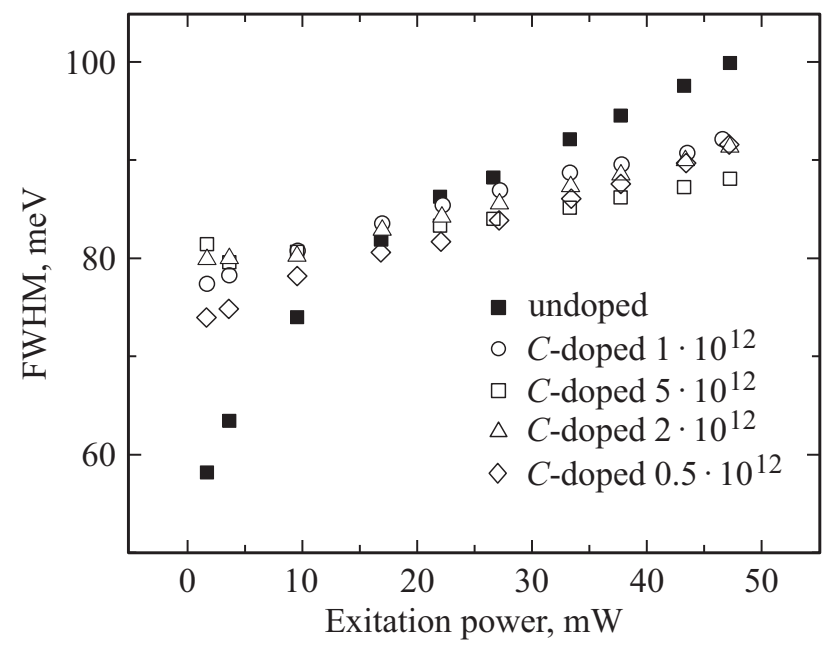

Рис. 2. Зависимость FWHM спектра фотолюминесценции от мощности лазерного возбуждения.

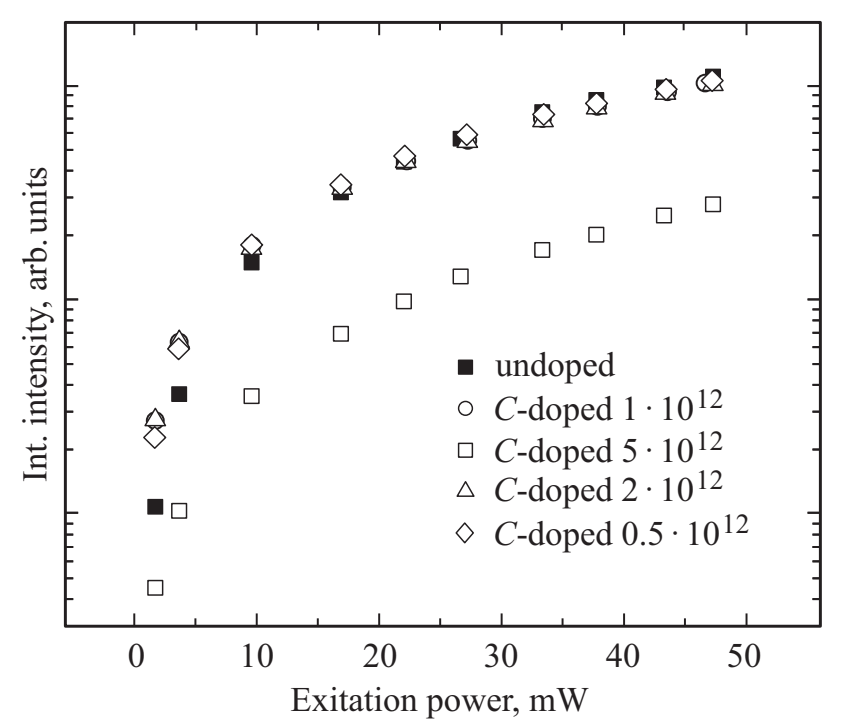

Рис. 3. Зависимость мощности фотолюминесценции от мощности возбуждения.

В случае нелегированной гетероструктуры электрон, попадая в КЯ, может рекомбинировать только с уже захваченными в КЯ дырками, спектр которых ограничен при малой накачке. С ростом накачки дырочные состояния заполняются, и полуширина спектра ФЛ сравнивается с полушириной спектра ФЛ легированной гетероструктуры. Дальнейший рост полуширины спектра ФЛ связан с тем, что уход электронов с основного уровня определяется скоростью захвата дырок на дырочный уровень, что ввиду дефицита дырок, приводит к „зависанию“ электронов на возбужденном уровне и росту излучательной рекомбинации через возбужденное состояние, и, как следствие, к росту полуширины спектра ФЛ.

На рис. 3 представлена зависимость интегральной интенсивности (мощности) излучения от мощности возбуждения. Видно, что интенсивность умеренно леги- 
рованных гетероструктур выше, чем у нелегированной гетероструктуры при малых значениях уровня возбуждения (менее 9мВт), при дальнейшем росте уровня возбуждения значения интегральной интенсивности гетероструктур сравниваются и практически насыщаются. Падение интегральной интенсивности гетероструктуры со степенью легирования $5 \cdot 10^{12} \mathrm{~cm}^{-2}$, по-видимому, связано с тем, что при таком высоком уровне легирования дно „потенциальной Кя““, образованной на месте $\delta$-слоя, расположено выше дырочного уровня Ферми, что приводит к образованию локального максимума дырочной плотности на месте $\delta$-слоя и к росту рассеяния на ионизованных примесях, и, как следствие, приводит к падению интенсивности излучательной рекомбинации. Схожий эффект, приводящий к падению концентрации электронов в канале транзистора с высокой подвижностью электронов, хорошо изучен [8].

Проведем анализ интегральной интенсивности (мощности) излучения от уровня возбуждения в предположении, что полная скорость излучательной рекомбинации в активной области объемом $V$ выражается $[9,10]$ :

$$
P=V B n^{2}
$$

где $n-$ концентрация носителей и $B-$ коэффициент излучательной рекомбинации, который не зависит от концентрации носителей ниже порога инверсии заселенности [11]. Далее предположим, что имеется два принципиальных канала безызлучательной рекомбинации. Первый связан с безызлучательной рекомбинацией, линейно зависящей от концентрации носителей, второй - это оже-рекомбинация, которая существенна в длинноволновых лазерах [12]. Тогда для полной скорости безызлучательной рекомбинации можно записать:

$$
K=V\left(\frac{n}{\tau_{n r}}+C n^{3}\right),
$$

где $\tau_{n r}-$ время безызлучательной рекомбинации Шоккли-Рида, $C$ - эффективный коэффициент ожерекомбинации. Будем считать, что рекомбинация вне активной области пренебрежимо мала, тогда для полного рекомбинационного тока можно записать

$$
I=e(P+K)
$$

где $e-$ заряд электрона. При проведении эксперимента очень сложно точно определить концентрацию носителей или полную выходную мощность $P$ (интегральная интенсивность). Однако использование линейного детектора мощности и неизменность условий измерений во время эксперимента позволяют относительно легко измерять фиксированную долю излучаемой интенсивности, т.е. интенсивность можно представить следующим образом:

$$
P_{\mathrm{ext}}=R P,
$$

где $P_{\text {ext }}$ - это выходная интегральная интенсивности (измеренная мощность), а $R$ - коэффициент пропорциональности между измеренной и излучаемой интенсивностями. Используя выражения (1)-(4), можно получить

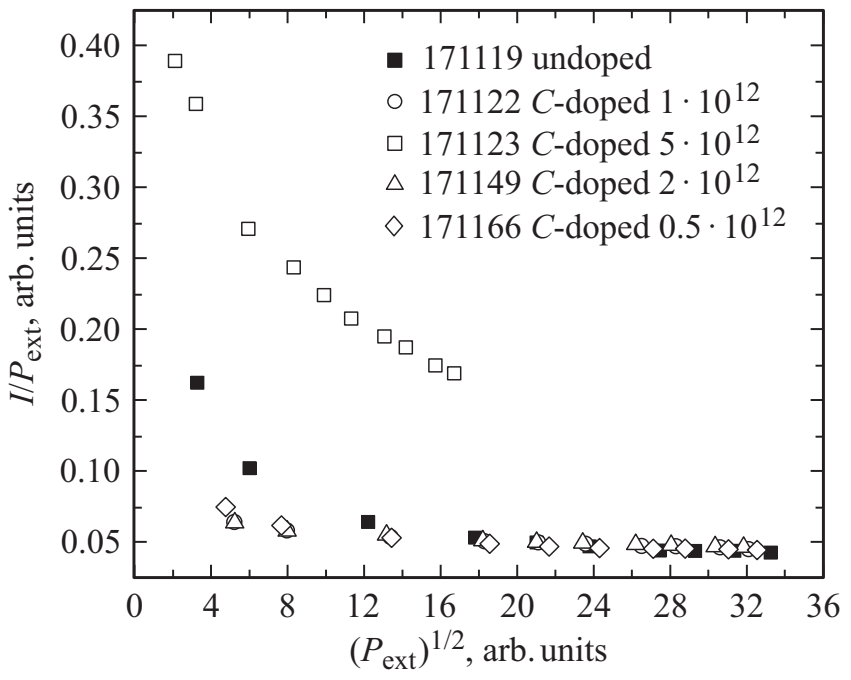

Рис. 4. Зависимость обратной эффективности спонтанной рекомбинации от корня из оптической мощности.

выражение для обратной эффективности спонтанной излучательной рекомбинации:

$$
\begin{aligned}
\frac{1}{P_{\mathrm{ext}}}= & \frac{e}{R}+\left(\frac{e^{2} V}{R}\right)^{1 / 2}\left(\frac{1}{\tau_{n r}^{2} B}\right)\left(\frac{1}{P_{\mathrm{ext}}}\right)^{1 / 2} \\
& +\left(\frac{e^{2}}{R^{3} V}\right)^{1 / 2}\left(\frac{C}{B^{3 / 2}}\right)\left(P_{\mathrm{ext}}\right)^{1 / 2}
\end{aligned}
$$

Таким образом, измерение зависимости выходной интегральной интенсивности спонтанного излучения от уровня возбуждения и последующая аппроксимация измеренной зависимости кривой вида (5) позволяют получить информацию о процессах безызлучательной рекомбинации в гетероструктурах.

На рис. 4 представлены зависимости обратной эффективности спонтанной рекомбинации от корня из выходной интегральной интенсивности. Аппроксимация экспериментальных данных кривой вида $A+B / x+C x$ позволяет легко вычислить коэффициенты при $\left(P_{\text {ext }}\right)^{1 / 2}$ и $\left(P_{\text {ext }}\right)^{-1 / 2}$.

Из рис. 4 видно, что использованный максимальный уровень оптической накачки - 43 мВт, который был ограничен возможностями измерительной установки, позволяет нам получить данные только для начального участка зависимости, описывающего время безызлучательной рекомбинации Шоккли-Рида $\left(\tau_{n r}\right)$. Влияние оже-рекомбинации при таких уровнях накачки несущественно.

На рис. 5 приведена зависимость отношения времени безызлучательной рекомбинации нелегированной гетероструктуры к времени безызлучательной рекомбинации легированных гетероструктур от уровня легирования, видно, что отношение времен имеет выраженный минимум при уровне легирования $(1-2) \cdot 10^{12} \mathrm{~cm}^{-2}$. Рост времени безызлучательной рекомбинации при увеличе- 


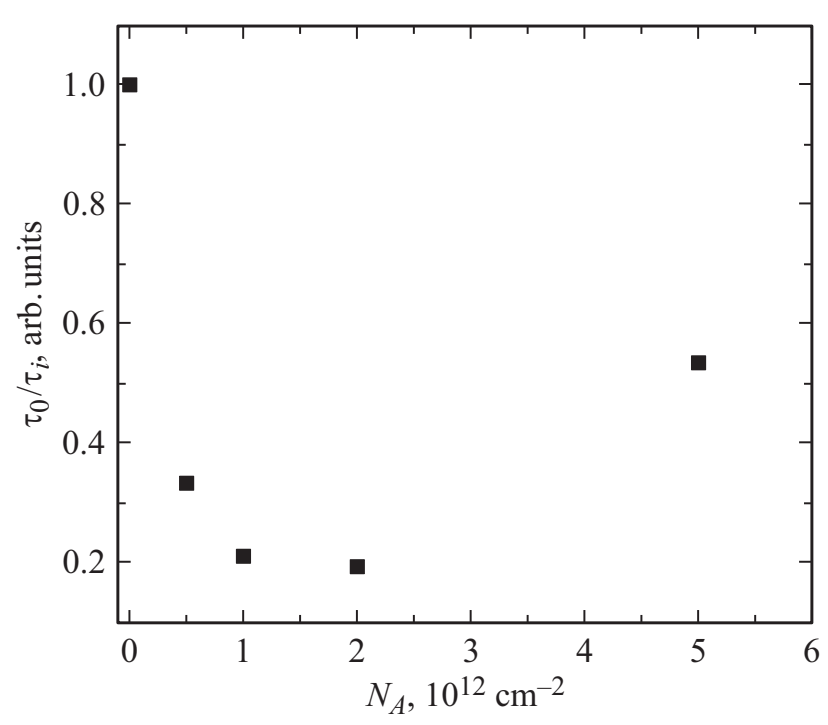

Рис. 5. Зависимость отношения времени безызлучательной рекомбинации нелегированной гетероструктуры к времени безызлучательной рекомбинации легированных гетероструктур от уровня легирования.

нии уровня легирования до $5 \cdot 10^{12} \mathrm{~cm}^{-2}$, по-видимому, связан с ростом рассеяния на ионизованных примесях.

\section{4. Заключение}

Методом молекулярно-пучковой эпитаксии на подложках InP выращены напряженные гетероструктуры с 9 КЯ InGaAs, излучающие в спектральном диапазоне $1520 \pm 10$ нм. Барьерные слои, разделяющие КЯ, были легированы углеродом (примесью $р$-типа). Легирование проводилось с использованием $\delta$-легирования в центре барьерного слоя. Уровень легирования составил $(0.5-1.0-2.0-5.0) \cdot 10^{12} \mathrm{~cm}^{-2}$. Показано, что легирование барьеров до уровня $(1-2) \cdot 10^{12} \mathrm{~cm}^{-2}$ приводит к росту интенсивности ФЛ при малых уровнях накачки и существенному подавлению безызлучательной рекомбинации. Полученные результаты могут быть использованы при проектировании и оптимизации активной области полупроводниковых лазеров различного типа.

Работа выполнена при поддержке Министерства образования и науки РФ в рамках Федеральной целевой программы „Исследования и разработки по приоритетным направлениям развития научно-технологического комплекса России на 2014-2020 годы“, соглашение № 14.578.21.0253, уникальный идентификатор RFMEFI57817X0253.

\section{Список литературы}

[1] R. Michalzik. VCSELs: Fundamentals, Technology and Applications of Vertical-Cavity Surface-Emitting Lasers (Springer International Publishing, London, 2013).
[2] S. Spiga, A. Andrejew, G. Boehm, M.-C. Amann. 2016 18th Int. Conf. Transparent Opt. Networks (Trento, Italy, 2016) p. 1.

[3] A.V. Babichev, A.S. Kurochkin, E.S. Kolodeznyi, A.G. Gladyshev, I.I. Novikov, L.Y. Karachinsky, A.Y. Egorov. Mater. Phys. Mech., 24 (3), 284 (2015).

[4] I.I. Novikov, A.V. Babichev, E.S. Kolodeznyi, A.S. Kurochkin, A.G. Gladyshev, V.N. Nevedomsky, S.A. Blokhin, A.A. Blokhin, A.M. Nadtochiy. Mater. Phys. Mech., 29 (1), 76 (2016).

[5] K.J. Vahala, C.E. Zah. Appl. Phys. Lett., 52 (23), 1945 (1988).

[6] K. Uomi. Jpn. J. Appl. Phys., 29 (1), 81 (1990).

[7] K. Uomi, T. Mishima, N. Chinone. Jpn. J. Appl. Phys., 29 (1), 88 (1990).

[8] Г.Б. Галиев, И.С. Васильевский, Е.А. Климов, В.Г. Мокеров, А.А. Черечукин. ФТП, 40 (12), 1479 (2006).

[9] K.R. Poguntke, A.R. Adams. Electron. Lett., 28 (1), 41 (1992).

[10] K. Mukai, Y. Nakata, K. Otsubo, M. Sugawara, N. Yokoyama, H. Ishikawa. IEEE J. Quant. Electron., 36 (4), 472 (2000).

[11] Б.Л. Гельмонт, Г.Г. Зегря. ФТП, 25 (1), 2019 (1991).

[12] M.I. Dyakonov, V.Y. Kachorovskii. Phys. Rev. B, 49 (24), 17130 (1994).

Редактор Г.А. Оганесян

\section{Effect of barrier layers doping on the photoluminescence efficiency of strained InGaAIAs/InGaAs/InP heterostructures}

E.S. Kolodeznyi ${ }^{1}$, A.S. Kurochkin ${ }^{1}$, S.S. Rochas ${ }^{1}$, A.V. Babichev ${ }^{1}$, I.I. Novikov ${ }^{1}$, A.G. Gladyshev' ${ }^{1}$, L.Ya. Karachinsky ${ }^{2}$, A.V. Savelyev ${ }^{1,3}$, A. Yu. Egorov' ${ }^{1}$, D.V. Denisov ${ }^{2,4}$

${ }^{1}$ ITMO University, 197101 St. Petersburg, Russia

${ }^{2}$ Connector Optics LLC,

194292 St. Petersburg, Russia

${ }^{3}$ St. Petersburg Academic University, 194021 St. Petersburg, Russia

${ }^{4}$ St. Petersburg State Electrotechnical University „LETI“, 197376 St. Petersburg, Russia

Abstract We studied the photoluminescence of InGaAlAs/ InGaAs/InP strained heterostructures grown by molecular beam epitaxy on an $\operatorname{InP}(100)$ substrate with an active region and consisted of 9 quantum wells $\mathrm{In}_{0.74} \mathrm{Ga}_{0.26}$ As and $\delta$-doped barriers $\mathrm{In}_{0.53} \mathrm{Al}_{0.20} \mathrm{Ga}_{0.27} \mathrm{As}$. Analysis of the photoluminescence spectra showed that $p$-type doping leads to an increase in the photoluminescence efficiency at a low excitation level in comparison with the heterostructure with undoped barriers, and the doping of the barriers to a level $(1-2) \cdot 10^{12} \mathrm{~cm}^{-2}$ leads to a suppression of nonradiative recombination. 